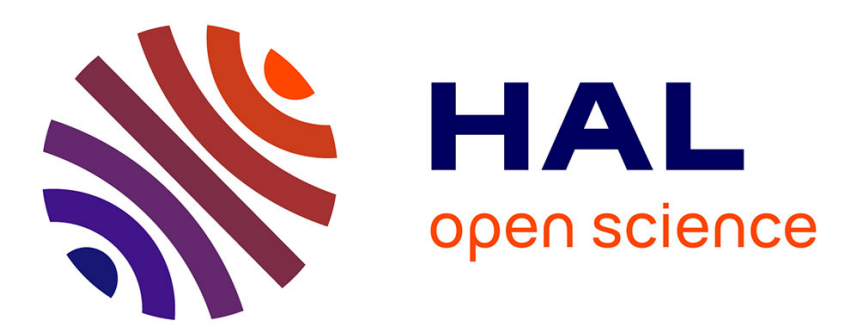

\title{
Surface integrity predictions and optimisation of machining conditions in the turning of AISI H13 tool steel \\ José Outeiro
}

\section{- To cite this version:}

José Outeiro. Surface integrity predictions and optimisation of machining conditions in the turning of AISI H13 tool steel. International Journal of Machining and Machinability of Materials, 2014, 15 (1/2), pp.122-134. hal-01063683

\section{HAL Id: hal-01063683 https://hal.science/hal-01063683}

Submitted on 12 Sep 2014

HAL is a multi-disciplinary open access archive for the deposit and dissemination of scientific research documents, whether they are published or not. The documents may come from teaching and research institutions in France or abroad, or from public or private research centers.
L'archive ouverte pluridisciplinaire HAL, est destinée au dépôt et à la diffusion de documents scientifiques de niveau recherche, publiés ou non, émanant des établissements d'enseignement et de recherche français ou étrangers, des laboratoires publics ou privés. 


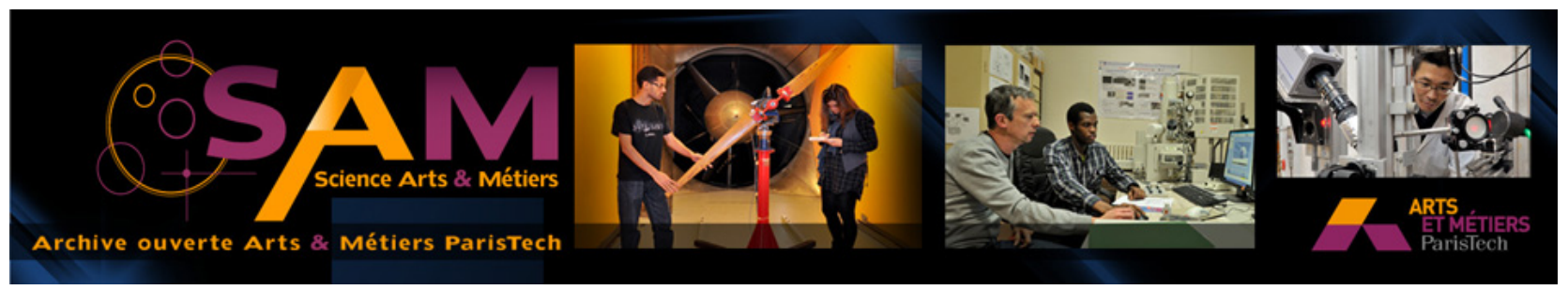

Science Arts \& Métiers (SAM)

is an open access repository that collects the work of Arts et Métiers ParisTech researchers and makes it freely available over the web where possible.

This is an author-deposited version published in: http://sam.ensam.eu

Handle ID: .http://hdl.handle.net/10985/8506

\section{To cite this version :}

José OUTEIRO - Surface integrity predictions and optimisation of machining conditions in the turning of AISI H13 tool steel - International Journal of Machining and Machinability of Materials Vol. 15, n¹/2, p.122-134 - 2014 


\title{
Surface integrity predictions and optimisation of machining conditions in the turning of AISI H13 tool steel
}

\author{
J.C. Outeiro
}

Arts et Metiers ParisTech, Rue Porte de Paris, 71250 Cluny, France

E-mail: jose.outeiro@ensam.eu

\begin{abstract}
Surface integrity (SI) plays a very important role in functional performance. It is dependent on a large number of machining parameters. The major concern of industry is to know which combination of machining parameters provides the best SI of machined components. Traditionally, surface roughness is considered to be the principal parameter to assess the SI of a machined part. However, residual stresses also become an important parameter because they control the lifetime of components (moulds, dies, etc.) and their abilities to withstand severe thermal and mechanical cyclic loadings (fatigue) during service. Therefore, significant improvements in the quality of the mould/die can be achieved with the control of residual stresses and surface roughness, both induced by machining. This paper examines both residual stresses and surface roughness induced by the dry turning of AISI H13 tool steel with different hardnesses. SI parameters were evaluated experimentally with respect to tool geometry, cutting speed, feed and depth of cut. A modelling and optimisation procedure based on artificial neural network (ANN), response surface methodology (RSM) and genetic algorithm (GA) approaches was developed and applied to identify the optimum combination of cutting parameters, leading to the best SI for machined components.
\end{abstract}

Keywords: surface integrity; residual stresses; surface roughness; modelling; optimisation.

Reference to this paper should be made as follows: Outeiro, J.C. (2014) 'Surface integrity predictions and optimisation of machining conditions in the turning of AISI H13 tool steel', Int. J. Machining and Machinability of Materials, Vol. 15, Nos. 1/2, pp.122-134.

Biographical notes: J.C. Outeiro received his $\mathrm{PhD}$ in Manufacturing Engineering from the University of Coimbra (Coimbra, Portugal) in 2003. He is an Associate Professor at Arts et Metiers ParisTech. He develops his research activities at $\mathrm{LaBoMaP}$ on surface integrity and modelling and simulation machining operations. He has been involved in several machining projects in cooperation with several academic and industrial partners in Europe and USA. His main research interest is the optimisation of machining operations with special emphasis on the quality of the machined components. His work is published in several peer-reviewed scientific journals and conference proceedings on machining related research topics.

This paper is a revised and expanded version of a paper entitled 'Optimization of machining parameters for improved surface integrity of AISI H13 tool steel' presented at 7th Conference on High Speed Machining (MUGV 2012), Saint-Etienne, France, October 2012. 


\section{Introduction}

The aeronautical, energy and biomedical industries are increasingly concerned with integrating absolute reliability and maximum safety in the functional performance of machined components. Surface integrity (SI) plays a very important role in this functional performance and depends on a large number of machining parameters. Therefore, the major concern of the industry is to know which combination of machining parameters provides the best SI for the machined components.

The machined material we considered was AISI H13 tool steel. It is characterised by a good resistance to thermal softening, high hardenability, high strength and high toughness. This steel has therefore been widely used to produce many different types of hot working dies, such as forging dies, extrusion dies, die-casting dies, etc. The process of making dies and moulds is one of the most demanding tasks in manufacturing engineering. Complex workpiece geometries, high material hardness and short lead times are among the main obstacles. At the same time, quality and reliability requirements are becoming more and more important, due to intensified competition and greater quality awareness. This quality and reliability is directly related to surface integrity (Jawahir et al., 2011). Traditionally, surface roughness is the principal parameter used to assess the SI of machined hot working dies made from AISI $13 \mathrm{H}$ tool steel. However, residual stresses are also becoming an important parameter. Their control during manufacturing will increase mould and die lifetime and their ability to withstand severe thermal and mechanical loading cycles (fatigue) in service. Significant improvements in the quality of the mould or die can therefore be achieved with the control of the residual stresses induced during its manufacturing.

Earlier SI studies in the machining AISI H13 tool steel focused mainly on the experimental assessment of the effects of cutting process parameters, tool geometry and tool wear on workpiece surface roughness, residual stress and subsurface alteration, such as white layer formation. The residual stresses induced by machining AISI H13 tool steel have mostly investigated for orthogonal cutting and milling operations, using polycrystalline cubic boron nitride (PCBN) and coated or uncoated cemented carbide cutting tools. Axinte and Dewes (2002) studied the influence of cutting speed, feed and workpiece angle on residual stress induced by the high speed milling of AISI H13 (47-49 HRc) tool steel, using solid carbide ball nose end mills coated with TiAlN, cooled by compressed air. They found compressive surface residual stresses in the direction of feed motion, reaching $-760 \mathrm{MPa}$. Using a full factorial experimental design with two levels for each factor they concluded that all three cutting parameters significantly affect the residual stresses. In this case, increasing all three cutting parameters renders the surface residual stresses less compressive. Marques et al. (2006) analysed the residual stresses induced by the dry face milling of AISI H13 $(50 \mathrm{HRc})$ tool steel with improved machinability, using both coated cemented carbide (with edge hone) and PCBN (with chamfer) cutting tools. They found predominantly compressive residual stresses at the machined surface and subsurface, these stresses being more compressive when using the coated cemented carbide cutting tool. This difference in residual stresses is attributed to the different cutting speeds $(50 \mathrm{~m} / \mathrm{min}$ using the coated cemented carbide tool and $600 \mathrm{~m} / \mathrm{min}$ using PCBN), tool geometry and tool material. Outeiro et al. (2008) analysed the influence of tool geometry (tool cutting edge preparation), cutting speed, uncut chip thickness and tool wear on residual stress distribution in the machined surface and subsurface of AISI H13 $(51 \mathrm{HRc})$ using PCBN cutting tools under dry orthogonal cutting 
conditions. Although the residual stresses are predominantly compressive, their magnitude decreases, becoming in some cases tensile, as the cutting speed, uncut chip thickness and tool wear increase. Moreover, chamfered tools produce lower compressive or tensile residual stresses when compared with edge-honed tools.

The investigation of the residual stresses induced in machining AISI H13 tool steel is not restricted to experimental studies. Residual stress has been also modelled and simulated, mainly using FEM. Chen et al. (2006) have also used FE modelling and experimental procedures to investigate the effects of edge preparation and feed on tool life and residual stresses induced by the dry orthogonal cutting of AISI H13 (52 HRc) tool steel, using chamfered and honed PCBN cutting tools. They showed that, although chamfered tools produce slightly higher tensile residual stresses at the machined surface when compared with honed tools, the combination of high feed and chamfered tools produces greater and deeper compressive residual stresses in the sub-surface. Outeiro et al. (2007a) developed a two-dimensional FE model of the orthogonal cutting process of AISI H13 $(52 \mathrm{HRc})$ tool steel using PCBN cutting tools. They applied this model to investigate the influence of tool geometry, cutting regime parameters and tool wear on residual stress distribution in the machined surface and subsurface. They concluded that in order to reduce the magnitude of the surface residual stresses, the cutting speed should be increased, the uncut chip thickness (or feed) should be reduced and machining with honed tools having a large cutting edge radius produces better results than using chamfered tools. Moreover, tool wear should be controlled in order to reduce the magnitude of the surface residual stresses.

Regarding the application of artificial neural networks (ANN) to predict the residual stresses induced by machining, Ambrogio et al (2007) proposed a predictive hybrid model based on ANN and FEM that was applied to determine the in-depth residual stress profile for a given set of cutting conditions (cutting tool, work material and cutting regime parameters). This hybrid approach was also used to determine the cutting conditions based on a given residual stress profile.

To complete all these studies, the present paper examines the residual stresses and surface roughness induced by the dry turning of AISI H13 tool steel using coated cemented carbide and PCBN cutting tools. The full residual stress tensor and the surface roughness were evaluated experimentally with respect to tool geometry, cutting speed, feed and depth of cut. A modelling and optimisation procedure based on ANN and a genetic algorithm (GA) was developed and applied to identify the combination of cutting parameters which will induce compressive residual stresses in machined components as well as low surface roughness, since this combination will improve the fatigue life of components (Jawahir et al., 2011; M'Saoubi et al., 2008). In order to simplify the analysis, only one surface roughness and one surface residual stress parameter were selected for this optimisation procedure. They are the arithmetic average surface roughness $\left(R_{a}\right)$ and the maximum principal residual stresses $\left(S_{\max }\right)$, respectively.

\section{Experimental and modelling procedures}

\subsection{Experimental set-up, work materials and cutting conditions}

Turning tests were performed on a CNC lathe equipped with a specially designed experimental set-up for cutting forces and infrared temperature measurements (Outeiro 
et al., 2004). Longitudinal turning tests were performed on round bars of AISI H13 tool steel (work material hardnesses equal to 16, 46 and $51 \mathrm{HRc}$ ) using coated cemented carbide (TiCN/ $/ \mathrm{Al}_{2} \mathrm{O}_{3} / \mathrm{TiN}, \mathrm{CVD}$ coating) and PCBN cutting tools (low CBN contents, in this case $50 \% \mathrm{CBN}$ ). The mechanical properties of the AISI H13 tool steel and the cutting parameters and tool geometry are summarised in Table 1 and Table 2, respectively. All the tests were conducted under dry cutting conditions.

Table 1 Mechanical properties of AISI H13 tool steel at two hardnesses

\begin{tabular}{lcc}
\hline & $46 \mathrm{HRc}$ & $51 \mathrm{HRc}$ \\
\hline Yield tensile strength (MPa) & 1,280 & 1,520 \\
Ultimate tensile strength (MPa) & 1,420 & 1,810 \\
Young's modulus (GPa) & 210 & 210 \\
Poisson ratio & 0.3 & 0.3 \\
\hline
\end{tabular}

Table 2 Tool geometry and cutting parameters

\begin{tabular}{lcc}
\hline & Coated $W C$ & $P C B N$ \\
\hline Tool cutting edge radius $-r_{n}(\mu \mathrm{m})$ & $40 ; 50 ; 67$ & 15 \\
Tool nose radius $-r_{\varepsilon}(\mathrm{mm})$ & $0.4 ; 0.8 ; 1.2$ & 0.8 \\
Chamfer geometry & - & $20^{\circ} \times 0.1 \mathrm{~mm}$ \\
Normal rake angle $-\gamma_{n}\left({ }^{\circ}\right)$ & -6 & -8 \\
Normal flank angle $-\alpha_{n}\left({ }^{\circ}\right)$ & 6 & 8 \\
Inclination angle cutting edge $-\lambda_{s}\left({ }^{\circ}\right)$ & -6 & 0 \\
Tool cutting edge angle $-\kappa_{r}\left({ }^{\circ}\right)$ & $75 ; 95$ & 90 \\
Tool minor cutting edge angle $\left.-\kappa_{r}^{\prime}{ }^{\circ}\right)$ & 5 & 30 \\
Cutting speed $-v_{c}(\mathrm{~m} / \mathrm{min})$ & $80 ; 100 ; 130$ & $150 ; 200$ \\
Feed $-f(\mathrm{~mm} / \mathrm{rev})$ & $0.1 ; 0.15 ; 0.2$ & $0.05 ; 0.1 ; 0.15$ \\
Depth of cut $-a_{p}(\mathrm{~mm})$ & $0.2 ; 1 ; 1.5$ & $0.25 ; 0.5$ \\
\hline
\end{tabular}

The residual stress state in the superficial layers of the workpiece was analysed by the X-ray diffraction technique (XRD) using the $\sin ^{2} \psi$ method (Noyan and Cohen, 1987). The experiments were carried out on PROTO iXRD equipment, using the parameters listed in Table 2. The full residual stress tensor was determined for all the cutting conditions, in the directions shown in Figure 1, $\mathrm{Y}$ being the direction of primary motion (circumferential direction), $\mathrm{X}$ the direction of the feed motion (axial direction) and $\mathrm{Z}$ the direction normal to the machined surface. Based on the full stress tensor, the maximum and minimum principal stresses $\left(\mathrm{S}_{\max }\right.$ and $\left.\mathrm{S}_{\min }\right)$ were calculated.

Three surface roughness parameters $\left(R_{a}, R_{z}\right.$ and $\left.R_{\max }\right)$ were measured using a Perthometer S4P profilometer. The measurements were performed in the direction of feed motion (axial direction) with a trace length of $4.8 \mathrm{~mm}$, using a Gaussian M1 band-pass filter with a cut-off length of $0.8 \mathrm{~mm}$. Each surface roughness was an average value taken from five measurements. 
Figure 1 Workpiece motion and directions of residual stress measurements

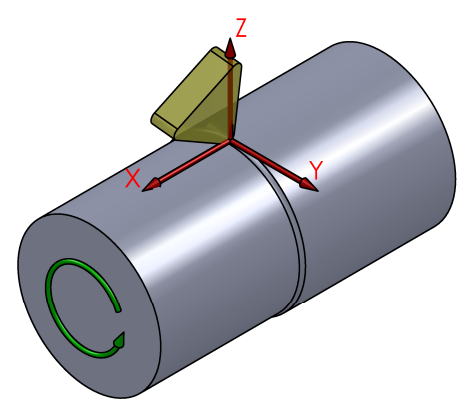

\subsection{Modelling and optimisation procedure and parameters}

The objective of the modelling and optimisation procedure was to find the optimal cutting conditions which induce low tensile or compressive residual stresses in the machined components and simultaneously low surface roughness. As shown in Figure 2, this procedure uses as input data the residual stress and surface roughness values obtained experimentally. It then uses the generalisation capability of the ANN to find the residual stress and surface roughness for a wide range of cutting conditions, and thus the residual stress and surface roughness function. This is the multiple-objective function which is used in the GA. The optimisation procedure was implemented in a computer program, developed using MATLAB.

Figure 2 Modelling and optimisation procedure (see online version for colours)

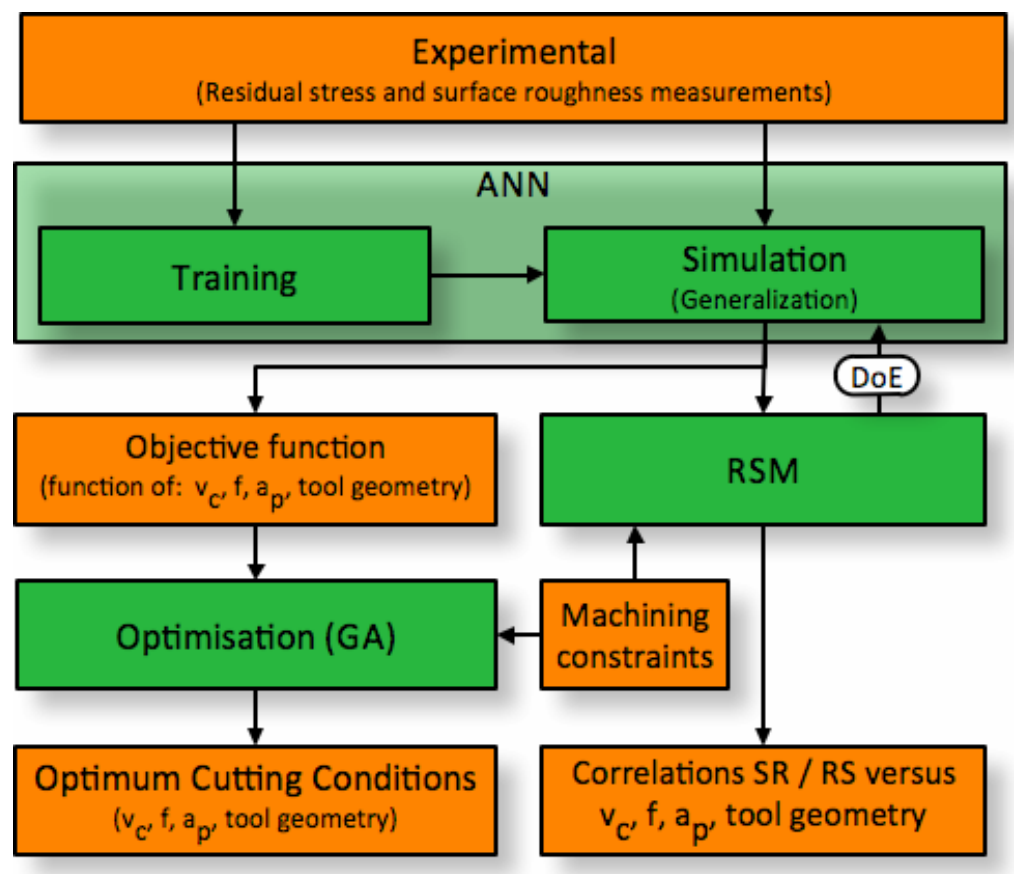




\subsubsection{Artificial neural network}

As shown in Figure 3(a), three layers compose the ANN: input, hidden and output. The input layer corresponds to the cutting $\left(\mathrm{v}_{\mathrm{c}}, \mathrm{f}, \mathrm{a}_{\mathrm{p}}\right)$ and tool geometry $\left(\kappa_{\mathrm{r}}, \mathrm{r}_{\varepsilon}\right.$ and $\left.\mathrm{r}_{\mathrm{n}}\right)$ parameters, having six neurons (total number of cutting conditions). An optimisation procedure was applied to determine the most advantageous number of neurons in the hidden layer, this number being equal to 50 . The output layer is composed of two neurons corresponding to the maximum principal residual stress $\left(\mathrm{S}_{\max }\right)$ and the arithmetic surface roughness $\left(\mathrm{R}_{\mathrm{a}}\right)$. Each neuron of the input layer is connected to each neuron of the hidden layer through weights and biases. The same process takes place between the each neuron of the hidden layer and each neuron of output layer.

Figure 3 (a) ANN and (b) GA architectures (see online version for colours)

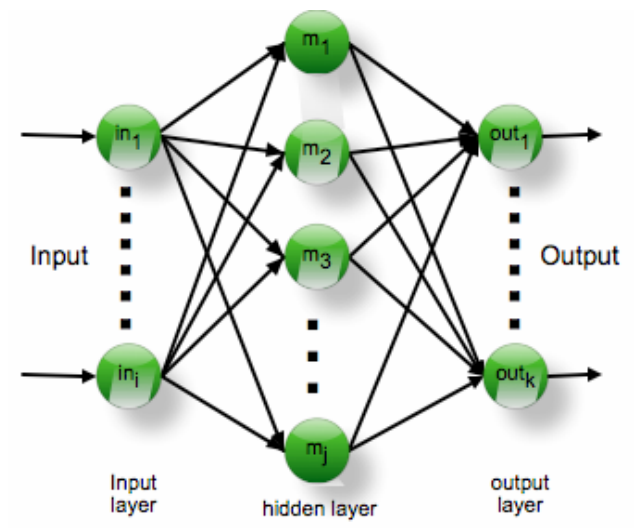

(a)

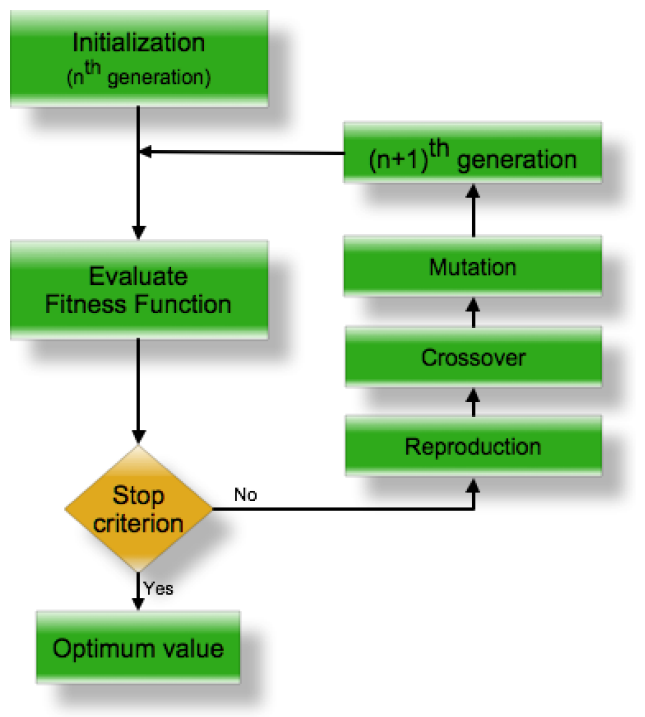

(b) 
$S_{\max }$ was selected due to its higher tensile values when compared to $S_{\min }$; thus $S_{\max }$ is the most critical parameter for part performance. Regarding surface roughness, although the three surface roughness parameters $\left(R_{a}, R_{z}\right.$ and $\left.R_{\max }\right)$ have different values, they follow exactly the same trend with respect to the cutting conditions. This means that the optimal cutting conditions to be identified by the optimisation procedure will be independent of a particular choice of surface roughness parameter. Thus, the arithmetic surface roughness parameter $\left(\mathrm{R}_{\mathrm{a}}\right)$ will be used in this optimisation procedure.

The back propagation algorithm, together with Bayesian regularisation, was used in training the neural networks. In this way a good generalisation capability is obtained with a limited amount of data. Moreover, this approach reduces the possibility of overfitting.

A non-linear sigmoid activation function is used in the input-hidden layers and a linear activation function in the hidden-output layers. The input data are normalised in the range of $[-1,1]$. The weights and biases of the network are initialised to small random values to avoid immediate saturation in the activation functions. Throughout this study, the data set is divided into two sets, one for training and the other for validation. These two sets consist of six input parameters $\left(v_{c}, f, a_{p}, \kappa_{r}, r_{\varepsilon}\right.$ and $\left.r_{n}\right), S_{\max }$ and $R_{a}$. The data for the training and validation sets were selected to cover the entire domain of the input data.

\subsubsection{Response surface methodology}

Response surface methodology (RSM) is a collection of mathematical and statistical techniques that are useful for the modelling and analysis of problems in which the output or response of interest is influenced by several variables and the objective is to find the correlation between the response and the variables (Montgomery, 2001). However, RSM can be also used to optimise the response. A prior knowledge of the studied process is thus necessary to achieve a realistic model.

RSM was used to obtain the correlations between the six input parameters $\left(v_{c}, f, a_{p}\right.$, $\kappa_{\mathrm{r}}, \mathrm{r}_{\varepsilon}$ and $\mathrm{r}_{\mathrm{n}}$ ) and the predicted $\mathrm{S}_{\max }$ and Ra. First, a Box-Behnken design of experiments (DoE) was used to generate several combinations of the six input parameters to be simulated by the ANN. For each input parameter three levels were selected. Each parameter was varied between a minimum and a maximum value, covering the range of the experimental input data. For each combination of the six input parameters, the ANN calculated the $\mathrm{S}_{\max }$ and the Ra. Then the correlations between the cutting parameters and the predicted $\mathrm{S}_{\max }$ and $\mathrm{Ra}$ were derived.

\subsubsection{Genetic algorithm}

The objective of the GA is to find the optimum set of cutting conditions $\left(v_{c}, f, a_{p}, \kappa_{r}, r_{\varepsilon}\right.$ and $r_{n}$ ), inducing compressive residual stress in the machined component as well as low surface roughness (minimisation). This search is performed for the range of cutting conditions (including tool geometry) presented in Table 1 and under specific machining constraints.

Figure 3(a) shows the architecture of the GA model, which is characterised by:

1 A fitness function or multi-objective function, which is created by the ANN.

2 The number of variables of the objective function was 6, corresponding to the total number of cutting conditions. 
3 Constraints: the cutting or machining conditions must be in the range of the experimental input data (avoidance of extrapolation).

4 The population at each generation is composed of 100 individuals (population size).

5 For this population size, the elite children are set to 10 , and the crossover fraction is 0.8 . Thus, the numbers of each type of child in the next generation are:

- ten elite children

- from the remaining 90 individuals, $80 \%$ will be the number of crossover children and $20 \%$ will be number of mutation children.

6 The algorithm stops as soon as any one of the following conditions is met (stopping criteria):

- the maximum number of generations is equal to 40

- the tolerance of the objective function becomes less than 1E-20.

\section{Results and discussion}

\subsection{Experimental results}

Figure 4 shows $S_{\max }$ and $S_{\min }$ at the machined surface for all the samples. While $\mathrm{S}_{\max }$ is always tensile, reaching values higher than $1,500 \mathrm{MPa}, \mathrm{S}_{\min }$ can be tensile or compressive.

Figure 4 Surface residual stresses for all the tested conditions (see online version for colours)

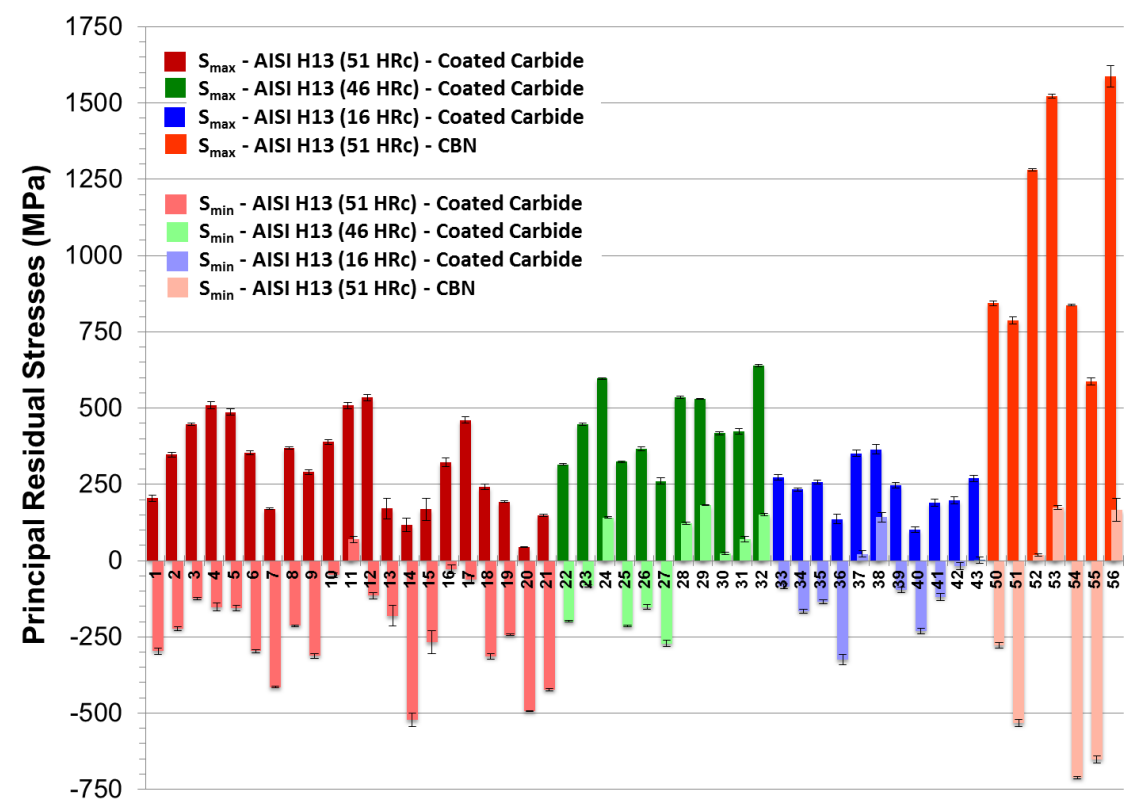


Figure 5 Surface roughness for all the tested conditions (see online version for colours)

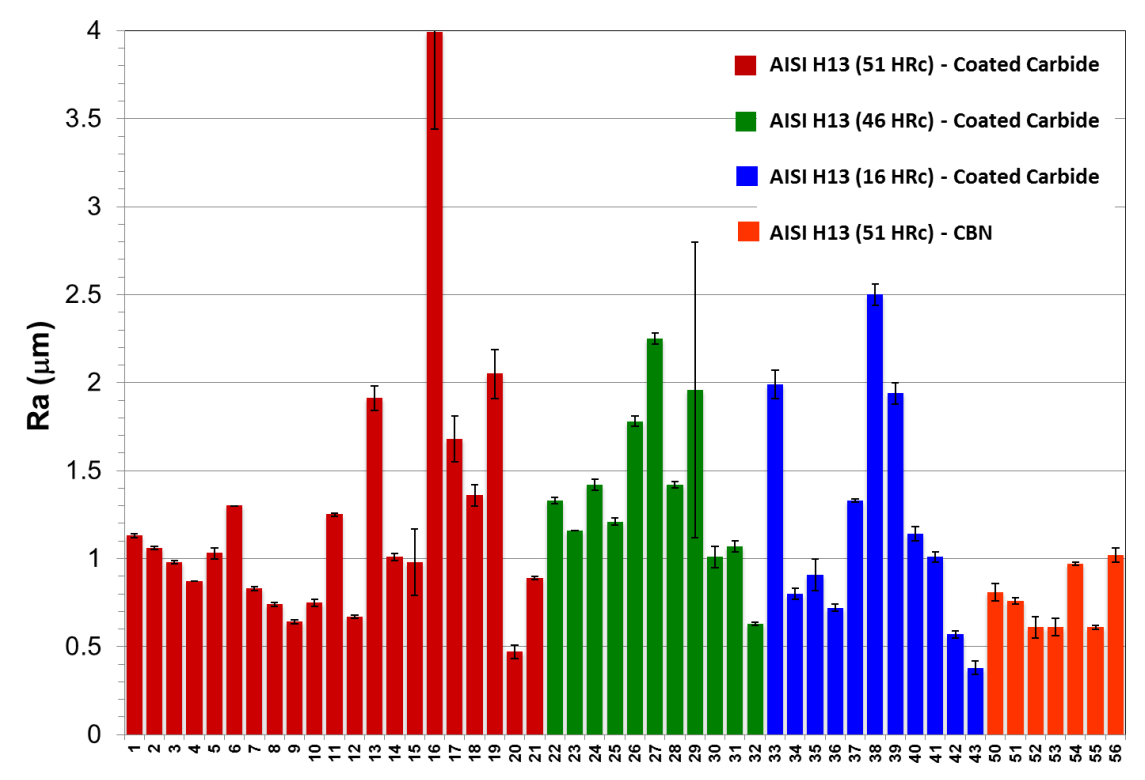

The PCBN cutting tool generates higher tensile residual stress values when compared to those generated by the coated cemented carbide cutting tool. The tendency of the PCBN cutting tool to increase the residual stresses was also reported by Marques et al. (2006). When comparing with the coated cemented carbide cutting tools, the higher negative effective tool rake angle of the PCBN chamfered tools, combined with its lower thermal conductivity ( $44 \mathrm{~W} / \mathrm{mK}$ for the PCBN and $100 \mathrm{~W} / \mathrm{mK}$ for the coated cemented carbide) (Jawahir and Van Luttervelt, 1993), will conduct more thermal energy to the workpiece (Outeiro et al., 2006). As a consequence, higher tensile residual stresses are generated when machining with PCBN tools when compared with coated cemented carbide tools.

Regarding the influence of the work material hardness, the tensile residual stresses seem to be lower for the lowest workpiece hardness. As shown in Table 1, the yield tensile stress increases with the material's hardness, so the corresponding residual stresses are also expected to increase with hardness. This relationship between work material hardness and residual stresses was investigated by Matsumoto et al. (1986).

As for surface roughness, the influence of the cutting tool is the opposite of that concerning residual stresses, i.e., the $\mathrm{CBN}$ cutting tool generates a lower surface roughness when compared to the coated cemented carbide tool. Regarding the influence of work material hardness, surface roughness is practically not affected by this parameter.

In conclusion, the PCBN cutting tool and the associated cutting parameters seem to be a good choice for improving surface finishing, but a poor choice concerning the residual stress state in the machined surface.

Considering these results and taking into account the fact that dry hard machining is increasingly used in industry, the following optimisation study will be performed only for a work material hardness of $51 \mathrm{HRc}$, using coated cemented carbide cutting tools. Table 3 shows the cutting conditions, the corresponding surface residual stresses $\left(S_{\max }\right.$ and $\left.S_{\min }\right)$, the direction of the maximum principal stress $(\theta)$ and the surface roughness values $\left(R_{a}\right)$. Since $S_{\max }$ is always tensile and $S_{\min }$ predominantly compressive, $S_{\max }$ is critical for 
component performance in service; thus only this stress will be used in the modelling and optimisation procedure.

Table 3 Parameters used in XRD analysis

\begin{tabular}{ll}
\hline Young modulus $(\mathrm{GPa})$ & 210 \\
Poisson ratio & 0.29 \\
Radiation & $\mathrm{Cr}-\mathrm{K} \alpha$ \\
Bragg angle $2 \theta\left(^{\circ}\right)$ & $156,33(\mathrm{hkl})=(211)$ \\
Number of $\psi$ angles & 13 \\
$\psi$ tilt $\left(^{\circ}\right)$ & 5 \\
\hline
\end{tabular}

\subsection{Predicted results}

After training and verification, the ANN was applied to simulate the influence of cutting parameters on residual stresses and surface roughness. Using the RSM it was possible to analyse the influence of each cutting parameter on the maximum principal residual stress and surface roughness. Figure 6 shows the predicted maximum principal stress with respect to the cutting parameters. As shown in this figure, the most influential parameters for residual stress are the tool cutting edge angle and the feed. For the tested parameters, the variation in the maximum residual stress due to feed is $130 \mathrm{MPa}$ and that due to tool cutting edge angle is $160 \mathrm{MPa}$. In this case, high tool cutting edge angles combined with low feeds will produce the lowest tensile maximum principal residual stress values. The same conclusion was obtained when turning AISI 316L stainless steel (Outeiro et al., 2007b). As far as surface roughness is concerned, Figure 7 shows that the most influential parameters for surface roughness are the tool edge radius, tool nose radius, feed and depth of cut. The feed seems to have the same influence on both residual stresses and surface roughness. Thus the feed should be reduced in order to decrease both surface roughness and tensile surface residual stresses. To determine the optimal cutting conditions, the optimisation procedure based on the GA will be applied.

Figure 6 Influence of cutting conditions on predicted maximum principal residual stress (AISI H13 - 51 HRc; coated cemented carbide cutting tool; dry cutting)
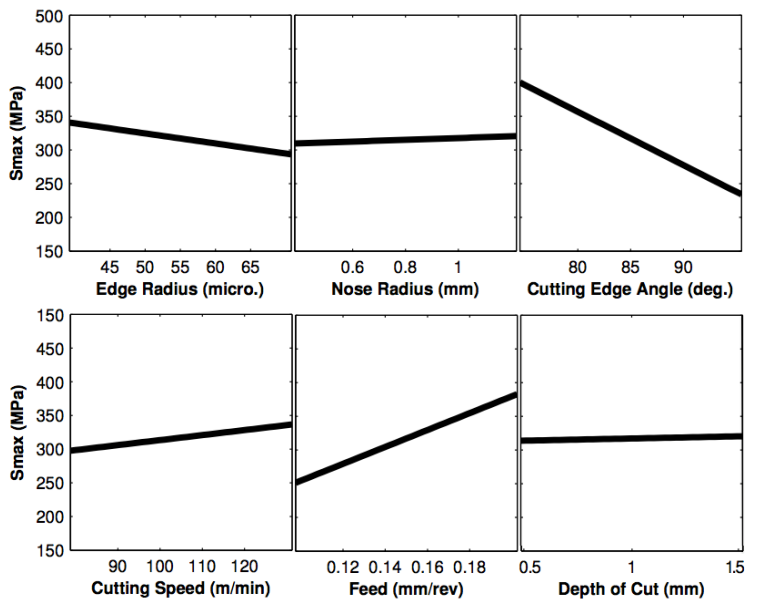
Figure 7 Influence of cutting conditions on predicted surface roughness

(AISI H13 -51HRc; coated cemented carbide cutting tool; dry cutting)
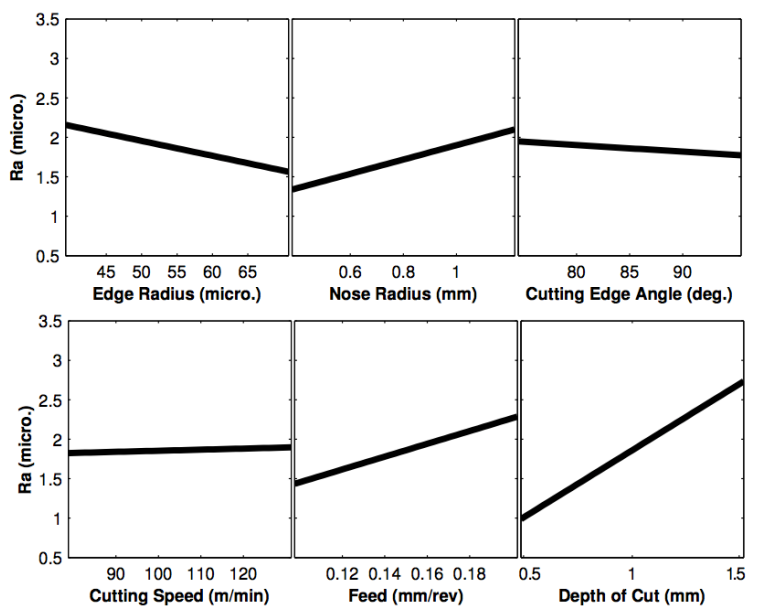

\subsection{Optimal cutting conditions}

In order to determine the optimal cutting conditions $\left(v_{c}, f, a_{p}, \kappa_{r}, r_{\varepsilon}\right.$ and $r_{n}$ ), the optimisation procedure based on the GA was applied. These optimal cutting conditions are shown in Table 4 , and induced simultaneously low tensile residual stress $\left(\mathrm{S}_{\max }\right)$ and low surface roughness $\left(\mathrm{R}_{\mathrm{a}}\right)$.

Table 4 Maximum and minimum principal residual stresses $\left(\mathrm{S}_{\max }\right.$ and $\left.\mathrm{S}_{\min }\right)$, direction of $\mathrm{S}_{\max }(\theta)$ and surface roughness $\left(\mathrm{R}_{\mathrm{a}}\right)$ for AISI H13 tool steel $(51 \mathrm{HRc})$

\begin{tabular}{lcccccccccc}
\hline $\begin{array}{l}\text { Test } \\
\text { number }\end{array}$ & $\begin{array}{c}r_{n} \\
(\mu \mathrm{m})\end{array}$ & $\begin{array}{c}r_{\varepsilon} \\
(\mathrm{mm})\end{array}$ & $\begin{array}{c}K_{r} \\
\left({ }^{\circ}\right)\end{array}$ & $\begin{array}{c}v_{c} \\
(\mathrm{~m} / \mathrm{min})\end{array}$ & $\begin{array}{c}f \\
(\mathrm{~mm} / \mathrm{rev})\end{array}$ & $\begin{array}{c}a_{p} \\
(\mathrm{~mm})\end{array}$ & $\begin{array}{c}S_{\max } \\
(\mathrm{MPa})\end{array}$ & $\begin{array}{c}S_{\min } \\
(\mathrm{MPa})\end{array}$ & $\begin{array}{c}\theta \\
\left({ }^{\circ}\right)\end{array}$ & $\begin{array}{c}R_{a} \\
(\mu \mathrm{m})\end{array}$ \\
\hline 1 & 50 & 0.4 & 75 & 100 & 0.1 & 1.5 & 204 & -297 & 32.81 & 1.13 \\
2 & 50 & 0.4 & 75 & 100 & 0.1 & 1 & 347 & -224 & 30.4 & 1.06 \\
3 & 50 & 0.4 & 75 & 80 & 0.1 & 1 & 447 & -125 & 34.78 & 0.98 \\
4 & 50 & 0.4 & 75 & 130 & 0.1 & 1 & 510 & -152 & 25.71 & 0.87 \\
5 & 50 & 0.4 & 75 & 100 & 0.15 & 1 & 487 & -156 & 21.43 & 1.03 \\
6 & 50 & 0.4 & 75 & 100 & 0.2 & 1 & 353 & -297 & 34.8 & 1.3 \\
7 & 50 & 0.4 & 75 & 100 & 0.1 & 0.2 & 170 & -415 & 38.37 & 0.83 \\
8 & 50 & 0.4 & 75 & 80 & 0.1 & 0.2 & 369 & -214 & 39.3 & 0.74 \\
9 & 50 & 0.4 & 75 & 130 & 0.1 & 0.2 & 290 & -313 & 32.42 & 0.64 \\
10 & 50 & 0.4 & 75 & 100 & 0.15 & 0.2 & 389 & -47 & 33.53 & 0.75 \\
11 & 50 & 0.4 & 75 & 100 & 0.2 & 0.2 & 508 & 69 & 31.95 & 1.25 \\
12 & 50 & 0.4 & 75 & 100 & 0.1 & 0.2 & 534 & -115 & 33.3 & 0.67 \\
13 & 40 & 0.8 & 75 & 100 & 0.1 & 1.5 & 171 & -181 & 28.06 & 1.91 \\
14 & 50 & 0.4 & 95 & 100 & 0.1 & 1.5 & 117 & -521 & 34.67 & 1.01 \\
\hline
\end{tabular}


Table 4 Maximum and minimum principal residual stresses $\left(\mathrm{S}_{\max }\right.$ and $\left.\mathrm{S}_{\min }\right)$, direction of $\mathrm{S}_{\max }(\theta)$ and surface roughness $\left(\mathrm{R}_{\mathrm{a}}\right)$ for AISI H13 tool steel (51 HRc) (continued)

\begin{tabular}{lcccccccccc}
\hline $\begin{array}{l}\text { Test } \\
\text { number }\end{array}$ & $\begin{array}{c}r_{n} \\
(\mu \mathrm{m})\end{array}$ & $\begin{array}{c}r_{\varepsilon} \\
(\mathrm{mm})\end{array}$ & $\begin{array}{c}K_{r} \\
\left({ }^{\circ}\right)\end{array}$ & $\begin{array}{c}v_{c} \\
(\mathrm{~m} / \mathrm{min})\end{array}$ & $\begin{array}{c}f \\
(\mathrm{~mm} / \mathrm{rev})\end{array}$ & $\begin{array}{c}a_{p} \\
(\mathrm{~mm})\end{array}$ & $\begin{array}{c}S_{\max } \\
(\mathrm{MPa})\end{array}$ & $\begin{array}{c}S_{\min } \\
(\mathrm{MPa})\end{array}$ & $\begin{array}{c}\theta \\
\left({ }^{\circ}\right)\end{array}$ & $\begin{array}{c}R_{a} \\
(\mu \mathrm{m})\end{array}$ \\
\hline 15 & 40 & 0.8 & 95 & 100 & 0.1 & 1.5 & 168 & -267 & 36.68 & 0.98 \\
16 & 67 & 1.2 & 95 & 100 & 0.1 & 1.5 & 323 & -29 & 22.25 & 3.99 \\
17 & 40 & 0.8 & 75 & 100 & 0.1 & 1 & 461 & -62 & 30.76 & 1.68 \\
18 & 50 & 0.4 & 95 & 100 & 0.1 & 1 & 242 & -314 & 31.26 & 1.36 \\
19 & 40 & 0.8 & 95 & 100 & 0.1 & 1 & 193 & -243 & 30.12 & 2.05 \\
20 & 67 & 1.2 & 95 & 100 & 0.1 & 1 & 44 & -494 & 25.14 & 0.47 \\
21 & 50 & 0.4 & 95 & 100 & 0.1 & 0.2 & 148 & -424 & 33.09 & 0.89 \\
\hline
\end{tabular}

Table 5 Optimal combination of cutting conditions

\begin{tabular}{|c|c|c|c|c|c|c|}
\hline \multirow{2}{*}{$\begin{array}{l}\text { Work } \\
\text { material }\end{array}$} & \multicolumn{3}{|c|}{ Cutting tool } & \multirow{2}{*}{$v_{c}(\mathrm{~m} / \mathrm{min})$} & \multirow{2}{*}{$f(\mathrm{~mm} / \mathrm{rev})$} & \multirow{2}{*}{$a_{p}(\mathrm{~mm})$} \\
\hline & $r_{n}(\mu m)$ & $r_{\varepsilon}(\mu m)$ & $\kappa_{r}\left(\varphi^{\prime}\right)$ & & & \\
\hline $\begin{array}{l}\text { AISI H13 } \\
(51 \mathrm{HRc})\end{array}$ & 60 & 0.4 & 95 & 118 & 0.1 & 0.4 \\
\hline
\end{tabular}

\section{Conclusions}

This work analyses the residual stresses and surface roughness generated by the longitudinal turning of AISI H13 (51 HRc) tool steel, using coated cemented carbide and PCBN cutting tools. The cutting speed was varied from 80 to $200 \mathrm{~m} / \mathrm{min}$, the feed from 0.05 to $0.2 \mathrm{~mm} / \mathrm{rev}$ and the depth of cut from 0.2 to $1.5 \mathrm{~mm}$. The full residual stress tensor was measured for the machined surface and the minimum and maximum principal residual stresses were calculated. The minimum principal residual stress is a compressive stress reaching about $-700 \mathrm{MPa}$, while the maximum principal residual stress is tensile, reaching about 1,550 $\mathrm{MPa}$, and thus critical for the component's performance in service. The surface roughness varied between 0.4 and $4 \mu \mathrm{m}$. When compared to the coated cemented carbide cutting tool, the PCBN generates higher values for tensile residual stress but lower values for surface roughness. The main reasons for these higher tensile residual stresses are probably the higher negative effective tool rake angle and the lower thermal conductivity of the CBN material.

A modelling and optimisation procedure based on ANN and GA was developed and applied to predict both residual stresses and surface roughness. The objective was to identify the optimum combination of cutting parameters. The ANN was trained and used to simulate both residual stresses and surface roughness for different combinations of machining parameters. Next, an RSM was applied to evaluate the influence of each cutting parameter on the residual stresses and surface roughness. In order to decrease the magnitude of the tensile residual stresses and surface roughness, both feed and depth of cut must be reduced, while the cutting edge angle must be increased. Finally, the optimal cutting conditions inducing low tensile residual stresses and low surface roughness were identified using the GA. 


\section{Acknowledgements}

Part of this work was developed at the X-Ray Center for Materials Research, University of Coimbra, Portugal. The work materials and cutting tools used in this work were provided by F. RAMADA and SECO TOOLS, respectively. The author gratefully acknowledges their support.

\section{References}

Ambrogio, G. et al. (2007) 'Integration of numerical simulation and neural network to predict residual stresses in hard machining', in 10th CIRP International Workshop on Modeling of Machining Operations, Calabria, Italy, 27-28 August.

Axinte, D.A. and Dewes, R.C. (2002) 'Surface integrity of hot work tool steel after high speed milling-experimental data and empirical models', Journal of Materials Processing Technology, Vol. 127, No. 3, pp.325-335.

Chen, L. et al. (2006) 'Effects of edge preparation and feed when hard turning a hot work die steel with polycrystalline cubic boron nitride tools', Annals of the CIRP, Vol. 55, No. 1, pp.89-92.

Jawahir, I.S. and Van Luttervelt, C.A. (1993) 'Recent developments in chip control research and applications', Annals of the CIRP, Vol. 42, No. 2, pp.659-693.

Jawahir, I.S. et al. (2011) 'Surface integrity in material removal processes: recent advances', CIRP Annals - Manufacturing Technology, keynote paper, Vol. 60, No. 2, pp.603-626.

M'Saoubi, R. et al. (2008) 'A review of surface integrity in machining and its impact on functional performance and life of machined products', International Journal of Sustainable Manufacturing, Vol. 1, Nos. 1-2, pp.203-236.

Marques, M.J. et al. (2006) 'Surface integrity of H13 ESR mould steel milled by carbide and CBN tools', Materials Science Forum, Vols. 514-516, pp.564-568.

Matsumoto, Y., Barah, M.M. and Liu, C.R. (1986) 'Effect of hardeness on the surface integrity of AISI 4340 steel', Journal of Engineering for Industry, Vol. 108, No. 3, pp.169-175.

MontGomery, D.C. (2001) Design and Analysis of Experiments, 5th ed., John Wiley \& Sons, New York.

Noyan, I.C. and Cohen, J.B. (1987) Residual Stress - Measurement by Diffraction and Interpretation, Society for Experimental Mechanics, Springer-Verlag, New York.

Outeiro, J.C. et al. (2007a) 'Modeling of tool wear and residual stress during machining of AISI H13 tool steel', in 9th International Conference on Numerical Methods in Industrial Forming Processes (NUMIFORM '07), AIP Conference Proceedings, FEUCP, Porto, Portugal.

Outeiro, J.C., Dillon, O.W. and Jawahir, I.S. (2007b) 'On designing for enhanced product sustainability by considering the induced residual stresses in machining operations', in Proceedings of the 2007 ASME International Mechanical Engineering Congress and Exposition, Seattle, Washington.

Outeiro, J.C. et al. (2008) 'Influence of cutting conditions on residual stresses induced by hard turning of AISI H13 tool steel', in 11th CIRP International Conference on Modeling of Machining Operations, NIST, Gaithersburg, MD, USA.

Outeiro, J.C., Dias, A.M. and Jawahir, I.S. (2006) 'On the effects of residual stresses induced by coated and uncoated cutting tools with finite edge radii in turning operations', Annals of the CIRP, Vol. 55, No. 1, pp.111-116.

Outeiro, J.C., Dias, A.M. and Lebrun, J.L. (2004) 'Experimental assessment of temperature distribution in three-dimensional cutting process', Machining Science and Technology, Vol. 8, No. 3, pp.357-376. 